\title{
Knowledge, and use of labour pain relief methods and associated factors among obstetric caregivers at public health centers of East Gojjam zone, Amhara region, Ethiopia: a facility based cross- sectional study
}

Keralem Anteneh Bishaw ${ }^{1 *}$, Endalew Gemechu Sendo ${ }^{2}$ and Workinesh Sinshaw Abebe ${ }^{2}$

\begin{abstract}
Background: The study was conducted in public health centers of East Gojjam Zone, Amhara region, Ethiopia. The purpose of this study was to assess knowledge, and use of labour pain relief methods and associated factors among obstetric caregivers in the study setting.

Methods: A facility-based cross-sectional study design was conducted from March 1-30, 2018. The study was conducted among three hundred and nine sampled obstetric caregivers. Structured questionnaire was used to collect the data. The data were entered into Epi-data version 4.2 Software for cleaning and exported to SPSS version 23.0 for data analysis. Multivariate logistic regression was carried out for variables with a $p$-value $<0.25$ in bivariate logistic regression to determine significant relationships between the dependent and independent variables. Statistical significance was determined at 95\% confidence interval (Cl) and p-value below 0.05 .

Result: The overall use of labour pain relief methods reported was 34.4\%, (30.4\% non-pharmacological and 8.4 pharmacological, respectively). More than half of the study participants (54.2\%) had adequate knowledge about labour pain relief methods. In multivariate analysis, being a midwifery profession [AOR $=2.814,95 \% \mathrm{Cl}=(1.574-$ 5.031)], having positive attitude $[A O R=4.370,95 \% \mathrm{Cl}=(2.523-7.567)]$, and professionals with a medium level of education $[A O R=3.450,95 \% \mathrm{Cl}=(1.993-5.971)]$ were factors significantly associated with knowledge of obstetric caregivers about labour pain relief methods. In multivariate analysis, knowledge of obstetric caregivers [AOR $=3.821$, 95\% Cl=(2.091-6.980)], positive attitude of obstetric caregivers $[\mathrm{AOR}=2.455,95 \% \mathrm{Cl}=((1.358-4.436))]$ and experience of obstetric caregivers $[A O R=2.56,95 \% \mathrm{Cl}=(1.350-4.845)$ were factors significantly associated with the use of labour pain relief methods.

* Correspondence: keralemante2010@gmail.Com

'Department of Midwifery, Debre-Markos University, College of Medicine and Health Sciences, Debre-Markos, Ethiopia

Full list of author information is available at the end of the article

C C The Author(s). 2020 Open Access This article is licensed under a Creative Commons Attribution 4.0 International License, which permits use, sharing, adaptation, distribution and reproduction in any medium or format, as long as you give appropriate credit to the original author(s) and the source, provide a link to the Creative Commons licence, and indicate if changes were made. The images or other third party material in this article are included in the article's Creative Commons licence, unless indicated otherwise in a credit line to the material. If material is not included in the article's Creative Commons licence and your intended use is not permitted by statutory regulation or exceeds the permitted use, you will need to obtain permission directly from the copyright holder. To view a copy of this licence, visit http://creativecommons.org/licenses/by/4.0/. The Creative Commons Public Domain Dedication waiver (http://creativecommons.org/publicdomain/zero/1.0/) applies to the data made available in this article, unless otherwise stated in a credit line to the data. 
(Continued from previous page)

Conclusion: In this study, the overall use of labour pain relief methods by obstetric caregivers was low. Systemic opioid (Pethdine) was reportedly one of the most known pharmacological pain relief methods in this study. Providers' knowledge, attitude and work experience had shown statistical significance with the use of labour pain relief methods. Task-oriented in- service training is required to fortify obstetric caregivers' knowledge and attitude towards the use of labour pain relief methods.

Keywords: Knowledge, Labour pain relief methods, Obstetric caregivers, Ethiopia

\section{Background}

Pain accompanies a human being since the beginning of his or her existence and is widely recognized as a negative phenomenon. In fact, it is an indispensable element of our life. It signals the worsening of health (called pathologic pain in that case), or it supports the progress of natural processes taking place in the body, e.g. during labour (physiological pain) [1].

Since creation, human beings have constantly felt pain and have always tried to control it in different ways. Labour pain is one of the most severe pains. This pain, as one of the inevitable aspects of the childbirth process, is unlike from other pains. It is not a sign of injury or (tissue damage), reduces spontaneously, is regular and continuous, gets tense gradually, and leads to a pleasant incident, which is childbirth [2].

Pain during labour is a central part of women's experience of childbirth, as its excruciating nature makes most women want to alleviate it. Childbirth is among one of the most intense pain that majority of women will endure during their lifetime $[3,4]$. Unresolved past psychological or physical distress along with loneness, lack of knowledge, unfriendly or unresponsive treatment during labour might surge the chance that the woman will suffer. In sub-Saharan Africa particularly in Nigeria, giving birth may not be an excited incident, however, it can be an unhappiness experience owing to some midwives' attitude towards the laboring woman who scream at labouring woman mainly when she cries or complains of labour pain [5].

Various pharmacologic and non-pharmacologic treatments have been developed to alleviate the labour pains; and their use has become popular, specifically in developed countries [6]. Pain relief during labour is desired by many women, irrespective of race or belief, and contributes enormously to their satisfaction with the experience of childbirth. Labour pain can be perceived to be the most severe form of pain experienced in a woman's life. Studies have shown that when women are offered analgesia during labour, they report greater satisfaction with their overall birth experience [7, 8].

A study in Southeast Nigeria among Igbo women reported $67.6 \%$ of labouring women need labor pain alleviation, however, only $27 \%$ of parturient received pain relief during labour [9]. Another study in Aga Khan teaching and referral hospital in Kenya found that 90\% of woman would request some form of labour pain relief at their next delivery but $18 \%$ had been offered some form of pain relief at their last delivery with $82 \%$ of those offered having effective pain relief as reported by the study participants [10].

Although labor pain management is accepted and implemented in many countries of the world, in Ethiopia pain management during labor is not a common practice. This might be as a result of a number of factors: the availability of drugs, health care delivery systems, limited knowledge, providers' attitude about labor pain management, and choice of caregivers and clients. Of these, the attitude, knowledge, and skills of the provider to offer labour analgesia are vital, particularly in lowincome countries, including Ethiopia [11, 12]. Therefore, this study aimed at assessing the level of knowledge, use of labour pain relief methods and associated factors among obstetric caregivers at public health centers of East Gojjam Zone, Amhara Region, Ethiopia.

\section{Methods}

Study design

A facility-based cross-sectional study was conducted.

\section{Study area and period}

The study was conducted in public health centers of East Gojjam Zone from March 1-30, 2018. East Gojjam is one of an administrative zone in Amhara regional state of Ethiopia. Debre Markos town is the capital city of East Gojjam zone, which is $265 \mathrm{Km}$ far from Bahirdar, the capital city of Amhara region and $299 \mathrm{Km}$ from Addis Ababa, the capital city of Ethiopia. According to 2010 Health Bureau of East Gojjam Zone, there were 100 public health centers, and 329 health officers, 797 nurses and 307 midwives working in the zone (district).

\section{Sample size, population and sampling technique}

We selected thirty-three (33) public health centers (33\%) out of 100 public health centers located in the study area by simple random sampling technique (lottery method). The source population of the study was health professionals in public health centers of East Gojjam Zone, 
Amhara region, Ethiopia. The study population was obstetric caregivers available during the study period in sampled health centers. Three hundred and nine (309) sampled obstetric caregivers; (including midwives, nurses, and health officers) who were giving obstetric care in the delivery room were consented and included in the study. Health care providers came to labour ward for consultation during study period were excluded from the study. Since there were small numbers of study population in the study area, all obstetric care caregivers, who were available during the study period were considered as study participants.

\section{Data collection tools and procedures}

A Structured pretested self-administered questionnaire was used to collect the data. The questionnaire was adapted from reviewed literature [13-15], and with some amendments into the local context. The questionnaire consisted of seven parts: the first part was used to assess socio-demographic characteristics of obstetric caregivers while the rest were used to assess the knowledge, attitude, use, preference of labour pain relief methods and institutional factors affecting the use of labour pain relief method. The questionnaire was designed in English to be understood by every study participants. Nine diploma nurses were recruited for data collection and two BSc midwives were hired for the supervision of data collection procedure.

\section{Measurement}

Knowledge about labour pain relief methods were measured by a 10-item knowledge questionnaire adapted from previous studies [13-15]. The scale for assessing knowledge were from 0 to 10 scores. Correct answers were given a score of 1 and incorrect answers 0 . Those who scored less than the mean value were considered to have inadequate knowledge while those who scored greater than or equal to the mean value were considered as having good knowledge.

Use of labor pain relief method was measured by the following question: Obstetric care provider who answered "yes" for the question "Have you ever provide any labor pain relief method in the past one month? Attitude towards labor pain relief method: A seven (7) item response options (Yes/No) were adapted from prior studies $[13,14]$. The total score were computed for each respondent and it ranges from 0 to 14 scores. Those who score less than the mean value were considered to have negative attitude while those who score greater than or equal to the mean value were considered as having positive attitude towards labour pain relief methods.

\section{Data quality control}

Training was provided for data collectors and supervisors on objective, the benefit of the study, individual's right and informed consent for the common understanding of the study in general and the questionnaire in particular. A pre - test was done in west Gojjam zone public health centers on $5 \%$ of obstetric caregivers two weeks before the actual data collection time. Regular supervision during data collection was made; the questionnaire was reviewed and checked for completeness, accuracy and consistency by the research team and supervisors.

\section{Data analysis}

First, the questionnaire was checked for completeness. The data were entered into Epi-data version 4.2 Software for cleaning and exported to SPSS version 23.0 for data analysis. Descriptive statistics were computed to determine frequencies and summary statistics (mean, standard deviation, and percentage) to describe the study population in relation to socio-demographic and other related variables. Bivariate logistic regression was carried out to see the association of each of the independent variables with the outcome variable. Multivariate logistic regression was then carried out for variables with a $p$ value $<0.25$ to determine significant relationships between the dependent and independent variables. Statistical significance was determined at $95 \%$ confidence interval (CI) and $p$-value below 0.05 .

\section{Results}

Socio demographic characteristics of respondents

Out of the 309 sampled obstetric caregivers, 299 responded to the questionnaires making a response rate of $96.8 \%$. The mean age of the respondents was 28.96 ( \pm $\mathrm{SD}=4.195)$ years. A significant number $194(64.9 \%)$ of them were in the age group of 20-29 years. More than half $162(54.2 \%)$ of the respondents were males and the majority (86.6\%) were Orthodox Christians. Out of the total respondents, $31.1 \%$ were midwives by their profession. Nearly half 149 (49.8\%) of study participants were diploma holders and $49.2 \%$ of them had BSc degree. Among the respondents (61.9\%) had work experience of less than 5 years (See Table 1).

\section{Knowledge of study participants about labour pain relief methods}

Majority (94.3\%) of respondents reported that they knew about labour pain management methods in general, of these 44 (14.7\%) knew pharmacologic and 58 (19.4\%) knew non-pharmacologic labour pain relief methods only. Nevertheless, 175 (58.5\%) of them reported that they knew both labour pain relief methods.

Among the study participants who knew pharmacologic methods, 174 (79.5\%) of them knew steroidal drugs, 130 (59.4\%) systemic opioid's, 75 (34.2\%) epidural analgesia and 24 (11\%) inhalational methods, 
Table 1 Socio-demographic characteristic of obstetric caregivers working at labour ward in public health centers of east Gojjam zone, Amhara region, Ethiopia, 2018 G.C. $(N=299)$

\begin{tabular}{|c|c|c|}
\hline Characteristics & Frequency (n) & Percent (\%) \\
\hline \multicolumn{3}{|l|}{ Age (in years) } \\
\hline $20-29$ & 194 & 64.9 \\
\hline $30-39$ & 97 & 32.4 \\
\hline$\geq 40$ & 8 & 2.7 \\
\hline \multicolumn{3}{|l|}{$\begin{array}{l}\text { Mean age: } 28.96 \\
( \pm S D=4.195)\end{array}$} \\
\hline \multicolumn{3}{|l|}{ Gender } \\
\hline Male & 162 & 54.2 \\
\hline Female & 137 & 45.8 \\
\hline \multicolumn{3}{|l|}{ Religion } \\
\hline Orthodox & 258 & 86.3 \\
\hline Muslim & 30 & 10 \\
\hline Protestant & 10 & 3.4 \\
\hline Other@ & 1 & 0.3 \\
\hline \multicolumn{3}{|l|}{ Profession } \\
\hline Health officer & 75 & 25.1 \\
\hline Midwife & 93 & 31.1 \\
\hline Nurse & 131 & 43.8 \\
\hline \multicolumn{3}{|c|}{ Level of education } \\
\hline Diploma & 149 & 49.8 \\
\hline BSc degree & 147 & 49.2 \\
\hline Masters & 3 & 1 \\
\hline \multicolumn{3}{|c|}{ Clinical experience (in years) } \\
\hline$\leq 5$ & 185 & 61.9 \\
\hline $6-9$ & 76 & 25.4 \\
\hline$\geq 10$ & 38 & 12.7 \\
\hline
\end{tabular}

Other $\odot=$ Catholic

respectively. Of all who knew about pharmacologic labour pain management methods, 161 (73.5\%) and 157 (71.7\%) of them reported delay progress of labour and fetal distress as a side effect of labour analgesia, respectively (See Fig. 1).

One hundred fifty-five $(51.8 \%)$ of respondents reported that they knew a WHO pain ladder. Among the study participants who knew non-pharmacologic labour pain relief methods, psychotherapy 217 (93.1\%), allow the mother to ambulate 188 (80.7\%), massage the back 175(75.1\%), show the woman how to bear down 127 (54.5\%) and allow companion of choice of labouring woman $110(47.2 \%)$ were the commonly reported nonpharmacologic labour pain relief methods (See Table 2).

In this study, out of the total respondents more than half $(54.2 \%)$ of obstetric care providers had adequate knowledge on listed types of labour relief methods (with
95\% CI $=48.55-59.85 \%)$ while the rest $137(45.8 \%)$ of respondents had inadequate knowledge about the listed labour pain relief methods.

\section{Attitude towards labour pain relief methods}

As regards the attitude of obstetric care givers towards labour pain relief methods, more than half $(57.2 \%)$ of them had positive attitude whereas $42.8 \%$ of them had negative attitude towards managing of labour pain. The majority (86.3\%) of the study participants believed managing of labour could help labouring woman to cope labour pain. However, $55.9 \%$ of them thought that pharmacologic labour pain relief method (analgesic) is not required for managing such labour pain.

\section{Use of labour pain relief methods}

The result of this study showed that the overall use of labour pain relief methods among obstetric caregivers was reported as $34.4 \%$ (30.4\% non-pharmacologic and 8.4\% pharmacologic pain relief methods) with $95 \%$ confidence interval of [29.01-39.78], respectively. From the non-pharmacologic labour pain management methods, psychotherapy was the most widely used method, which was prescribed by 132 (44.2\%) of obstetric caregivers followed by massaging the back 122(40.8\%) (See Table 3).

\section{Personal preference and pain expectation}

From the total study participants, most obstetric caregivers $(87.6 \%)$ expected labour pain as severe pain while (3.4\%) of them expected labour pain as moderate pain. Among the study participants, more than half (55.9\%) preferred non-pharmacologic methods while $10.7 \%$ of them preferred pharmacologic methods to manage labour pain, respectively. Diclofenac (51.2\%) was the highest reported preferred pharmacologic method followed by pethdine (34.1\%).

\section{Reasons for non-utilization of labour pain relief methods}

The most common reasons reported for non-utilization of labour pain relief methods were high patient flow 131 (43.8\%) followed by unavailability of drugs 124(41.5\%), respectively (See Fig. 2).

Of those who knew pharmacologic methods, 153 (51.2\%), 140 (46.8\%), $102(34.1 \%)$ and $93(31.1 \%)$ of study participants reported diclofenac, Paracetamol, Pethidine and Hyoscine were available in their health centers for use, respectively. Eighty-seven (29.1\%) of study participants reported companion as a choice for labouring woman is not allowed by their health center and $87 \%$ of them reported that they didn't get any special training on labour pain management. 


\section{Side effect of labour analgesia}

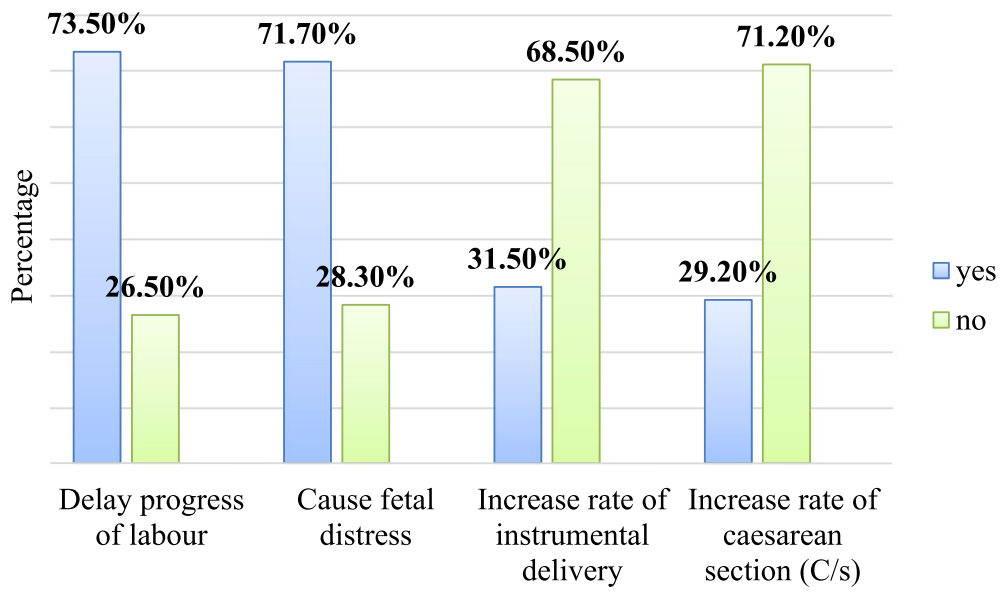

Fig. 1 Knowledge of obstetric caregivers on side effect of pharmacologic labour pain relief methods working at labour ward in public health centers of east Gojjam zone, Amhara region, Ethiopia, $2018(n=219)$

Factors associated with knowledge of obstetric caregivers towards labour pain relief methods

Profession categories, staff attitude, level of education, and companionship were significantly associated with

Table 2 Knowledge of obstetric caregivers on Non pharmacologic labour pain relief methods working at labour ward in public health centers of east Gojjam zone, Amhara region, Ethiopia, 2018 G.C. $(n=233)$

\begin{tabular}{llll}
\hline Types & & Frequency (n) & Percent (\%) \\
\hline Psychotherapy & Yes & 217 & 93.1 \\
& No & 16 & 6.9 \\
Allow the mother to ambulate & Yes & 188 & 80.7 \\
& No & 45 & 19.3 \\
Massage the back & Yes & 175 & 75.1 \\
& No & 58 & 24.9 \\
Allow free vertical positioning & Yes & 61 & 26.2 \\
Transcutaneous electrical & No & 162 & 73.8 \\
nerve stimulation & Yes & 13 & 5.6 \\
Show the woman how to bear down & Yes & 127 & 94.4 \\
Acupuncture & No & 106 & 54.5 \\
& Yes & 20 & 45.5 \\
Hypnosis & No & 213 & 8.6 \\
Allow companion of labouring & Yes & 13 & 91.4 \\
woman choice & No & 220 & 9.6 \\
Music therapy & Yes & 110 & 47.4 \\
& No & 123 & 53.8 \\
\hline & Yes & 42 & 18 \\
\hline & No & 181 & 82 \\
\hline
\end{tabular}

knowledge of obstetric caregivers about labour pain relief methods in bivariate logistic regression. These variables also remained significantly associated in multivariable logistic regression. Being midwifery professionals were 2.8 times more likely to be knowledgeable about labour pain relief methods than health officer and nurses. $[\mathrm{AOR}=2.814,95 \% \mathrm{CI}=(1.574-5.031)]$. Professionals with a medium level of education were 3.45 times more likely to be knowledgeable about labour pain relief methods compared to those with a lower level of education $[\mathrm{AOR}=3.450,95 \% \mathrm{CI}=(1.993-5.971)]$. Obstetric caregivers who had a positive attitude about

Table 3 Non -pharmacologic methods use by obstetric caregivers working at labour ward in public health centers of east Gojjam zone, Amhara region, Ethiopia, 2018 G.C. $(n=299)$

\begin{tabular}{llll}
\hline Types & Frequency & (n) & Percent (\%) \\
\hline Psychotherapy & Yes & 132 & 44.1 \\
& No & 167 & 55.9 \\
Allow the mother to ambulate & Yes & 116 & 38.8 \\
& No & 183 & 61.2 \\
Massage the back & Yes & 122 & 40.8 \\
Allow free vertical positioning & No & 177 & 59.2 \\
& Yes & 25 & 8.4 \\
Show the woman how to bear down & No & 274 & 91.6 \\
& Yes & 96 & 32.1 \\
Hot compress & No & 203 & 67.9 \\
Allow companion of her choice & Yes & 7 & 2.3 \\
& No & 292 & 97.7 \\
& No & 212 & 70.9 \\
\hline
\end{tabular}


Reasons for non use

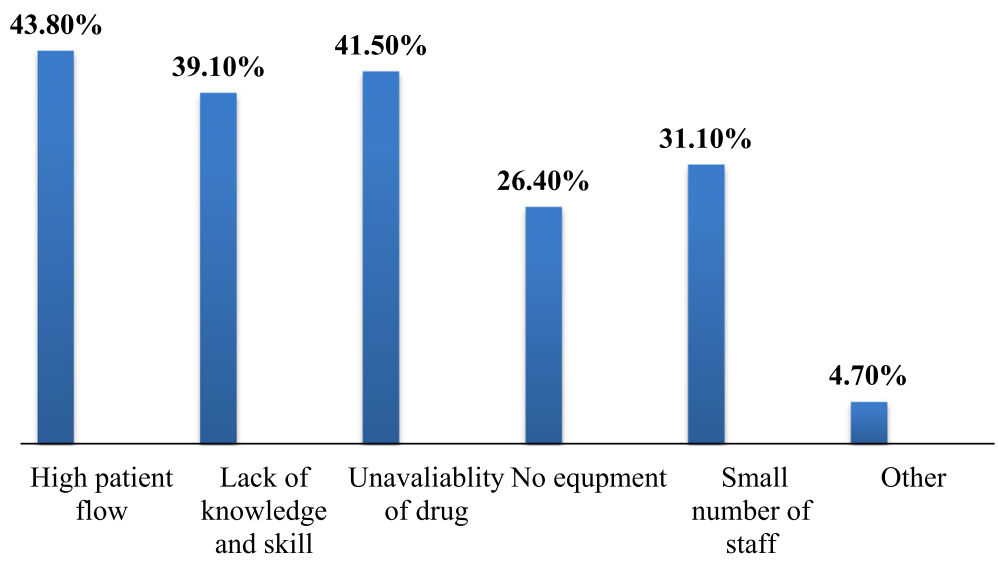

Fig. 2 Bar chart showing reasons for non-utilization of labour pain relief methods, 2018. $(n=299)$. Key: Other reasons: Free of side effect and labour pain is a natural process which should not be managed

labour pain management were 4.37 times more likely to be knowledgeable about labour pain management methods than those who had a negative attitude for labour pain management $[\mathrm{AOR}=4.370,95 \% \mathrm{CI}=$ (2.523-7.567)] (See Table 4).

\section{Factors associated with use of labour pain relief methods}

Bivariate logistic regression revealed that professional categories, knowledge, attitude, experience of obstetric caregivers and allowing a companion for a labouring woman were associated with the use of labour pain relief methods. But only knowledge, attitude and experience of obstetric caregivers remained significantly associated with the use of labour pain relief methods for labouring woman in multivariable logistic regression. Obstetric caregivers who had adequate knowledge about labour pain relief methods for managing labour pain were about 3.82 times more likely to use labour pain relief methods than to those obstetric caregivers who had inadequate knowledge about labour pain relief methods $[\mathrm{AOR}=$ $3.821,95 \% \mathrm{CI}=(2.091-6.980)]$.

Obstetric caregivers who had a positive attitude for managing labour pain were 2.45 times more likely to use labour pain management methods than those who had a negative attitude for labour pain management $[A O R=$ 2.455, 95\% CI $=((1.358-4.436))]$. Obstetric caregivers who had an experience of $6-9$ years and $\geq 10$ years were 2.56 and 2.50 more likely to use labour pain relief

Table 4 Bivariate and Multivariate analysis of factors associated with knowledge of obstetric caregivers towards labour pain relief methods east Gojjam zone, Amhara regional state, in Ethiopia, 2018. G.C. $(n=299)$

\begin{tabular}{|c|c|c|c|c|c|}
\hline \multirow{3}{*}{ Characteristics } & \multicolumn{2}{|c|}{ Knowledge of obstetric caregivers } & \multirow[t]{3}{*}{$\operatorname{COR}(95 \% \mathrm{Cl})$} & \multirow[t]{3}{*}{ AOR $(95 \% \mathrm{Cl})$} & \multirow[t]{3}{*}{$P$ Value } \\
\hline & Adequate & inadequate & & & \\
\hline & Frequency (n) & Frequency (n) & & & \\
\hline \multicolumn{6}{|l|}{ Profession } \\
\hline Midwife & $66(71 \%)$ & $27(29 \%)$ & $2.801(1.68-4.73)$ & $2.814(1.574-5.031)$ & .000 \\
\hline Others & $96(46.6 \%)$ & $110(53.4 \%)$ & 1.00 & 1.00 & \\
\hline \multicolumn{6}{|l|}{ Level of education } \\
\hline Lower & $68(43.6 \%)$ & $88(56.4 \%)$ & 1.00 & 1.00 & \\
\hline Medium & $94(65.7 \%)$ & $49(34.3 \%)$ & $2.483(1.55-3.97)$ & $3.450(1.993-5.971)$ & .000 \\
\hline \multicolumn{6}{|l|}{ Companion } \\
\hline Yes & $132(62.3 \%)$ & $80(37.7 \%)$ & $3.135(1.86-5.28)$ & $2.349(1.314-4.197)$ & .004 \\
\hline No & $30(34.5 \%)$ & $57(65.5 \%)$ & 1.00 & 1.00 & \\
\hline \multicolumn{6}{|l|}{ Attitude } \\
\hline Favorable attitude & $118(69 \%)$ & $53(31 \%)$ & $4.250(2.61-6.92)$ & $4.370(2.523-7.567)$ & 0.000 \\
\hline Un Favorable attitude & $44(34.4 \%)$ & $84(65.6 \%)$ & 1.00 & 1.00 & \\
\hline
\end{tabular}


methods than those who have $\leq 5$ years' experience $[\mathrm{AOR}=2.56,95 \% \mathrm{CI}=(1.350-4.845)$ and $[\mathrm{AOR}=2.50$, $95 \% \mathrm{CI}=(1.132-5.524)]$, respectively (See Table 5$)$.

\section{Discussion}

The current study aimed to assess knowledge and use of labour pain relief methods and associated factors among obstetric caregivers at public health centers of East Gojjam Zone, Amhara region, Ethiopia.

\section{Knowledge of obstetric caregivers towards labour pain relief methods}

In this study, systemic opioid (Pethdine) was reportedly one of the most identified pharmacological pain relief methods, which is similar with studies from Zaria, Greek, and Ibadan (Nigeria), respectively [6, 16, 17]. This might be due to accessibility and low cost of the drug on the market. The present study showed that $45.8 \%$ of obstetric caregivers had inadequate knowledge about labour pain relief methods. Our finding is lower than the findings reported from Tigray, Ethiopia (60.1\%) and Ibadan, Nigeria (66.7\%), respectively [13, 17]. This difference might be explained in terms of difference in study setting and socio- demographic characteristics of study participants. The study also found that midwifery professionals had adequate knowledge than health officer and nurses, which was similar with Australian studies undertaken by Lee et al (2012) [18], which reported knowledge as a significant factor for obstetric analgesia use. In our study, professionals with a medium level of education were 3.4 times more likely to be knowledgeable than those with a lower level of education regarding labour pain relief methods. This might be explained in terms of variation in curriculum content of obstetric courses delivered to health professions based on their level of training programs. Positive attitude of staff also showed significant association with knowledge with regard to labour pain relief methods.

\section{Use of labour pain relief methods among obstetric caregivers}

The current study showed that the overall use of labour pain relief methods among obstetric caregivers was reported to be $34.4 \%$ (30.4\% non-pharmacological and 8.4\% pharmacological) methods, respectively. This finding is inconsistent with earlier studies' findings from different parts of Ethiopia: Tigray, 43.3\% [13], Addis Ababa, 47.5\% [19] and Amhara, 40.1\% [14]. The reasons might be the preceding studies were conducted in public hospitals where better knowledge of labour pain relief methods and drug availability are potentially high.

In our study, the use of non-pharmacological methods was consistent with studies done in Dhaka, Bangladesh and Ghana where allowing laboring woman to move freely, showing the patient how to bear down, allowing companion, and massaging the back were the most

Table 5 Bivariate and Multivariate analysis of factors associated with use of labour pain relief methods among obstetric caregivers east Gojjam zone, Amhara regional state, in Ethiopia, 2018G.C. $(n=299)$

\begin{tabular}{|c|c|c|c|c|c|}
\hline \multirow{3}{*}{ Variables } & \multicolumn{2}{|c|}{ Use of labour pain relief methods } & \multirow[t]{3}{*}{$\operatorname{COR}(95 \% \mathrm{Cl})$} & \multirow[t]{3}{*}{ AOR $(95 \% \mathrm{Cl})$} & \multirow[t]{3}{*}{$P$ Value } \\
\hline & Yes & No & & & \\
\hline & Frequency (n) & Frequency (n) & & & \\
\hline \multicolumn{6}{|l|}{ Profession } \\
\hline Midwife & $40(44 \%)$ & $53(56 \%)$ & $1.713(1.032-2.842)$ & $1.435(.801-2.572)$ & .225 \\
\hline Others & $63(70.4 \%)$ & $143(29.6 \%)$ & 1.00 & 1.00 & \\
\hline \multicolumn{6}{|l|}{ Experience } \\
\hline$\leq 5$ years & $52(28.1 \%)$ & 133(71.9\%) & 1.00 & 1.00 & \\
\hline $6-9$ years & $32(42.1 \%)$ & $44(57.9 \%)$ & $1.860(1.066-3.246)$ & $2.56(1.350-4.845)$ & $.004^{*}$ \\
\hline$\geq 10$ year & 19(50\%) & 19(50\%) & $2.558(1.255-5.213)$ & $2.50(1.132-5.524)$ & $.023^{*}$ \\
\hline \multicolumn{6}{|l|}{ Knowledge } \\
\hline Inadequate & $22(16.1 \%)$ & 115(83.9\%) & 1.00 & 1.00 & \\
\hline Adequate & $81(50 \%)$ & $81(50 \%)$ & $5.227(3.015-9.063)$ & $3.82(2.091-6.980)$ & $.000^{*}$ \\
\hline \multicolumn{6}{|l|}{ Attitude } \\
\hline Favorable attitude & $79(46.2 \%)$ & $92(53.8 \%)$ & $3.721(2.177-6.360)$ & $2.46(1.358-4.436)$ & $.000^{*}$ \\
\hline Un Favorable attitude & $24(18.8 \%)$ & 104(81.2\%) & 1.00 & 1.00 & \\
\hline \multicolumn{6}{|l|}{ Companion } \\
\hline Yes & 84(39.6\%) & $128(60.3 \%)$ & $2.349(1.317-4.188)$ & $1.458(.761-2.793)$ & .256 \\
\hline No & $19(21.8 \%)$ & $68(78.2 \%)$ & 1.00 & 1.00 & \\
\hline
\end{tabular}


applied non-pharmacologic pain relief methods [20, 21]. This study found that the use of pharmacologic labour pain relief method by obstetric caregivers was reported to be $8.4 \%$ of which pethidine, diclofenac, paracetamol and Hyoscine were mostly used. This result is consistent with studies done in Bangladesh and Ghana, where these drugs were also used as pharmacological labour pain relief methods [20, 21].

On the other hand, this result is higher than the findings from studies done in Amhara region referral hospital [14] and Tigray region general hospital [13]. This might be due to time difference related to previous studies and increased awareness of obstetric caregivers towards labour pain management through time. Nonetheless, this result is found to be lower than the findings from Nigeria, 49\% [3], Kenya, 18\% [8] and Addis Ababa Ethiopia, 54.2\% [19], respectively.

This study revealed that obstetric caregivers who had a positive attitude for managing labor pain were 2.45 times more likely to use labor pain management methods than those who had a negative attitude for labour pain management $[\mathrm{AOR}=2.455,95 \% \mathrm{CI}=((1.358-4.436))]$. This finding is consistent with a study done in Bangladesh [20], and Ethiopia [15], respectively.

In this study, obstetric caregivers who had adequate knowledge about labour pain relief methods for managing labour pain were 3.82 times more likely to use labour pain relief methods than those who had inadequate knowledge about labour pain relief methods $[\mathrm{AOR}=3.821,95 \% \mathrm{CI}=(2.091-6.980)]$, which is inconsistent with studies from Nigeria and Abha Maternity Hospital in Saudi Arabia where health care providers who had adequate knowledge were more likely to provide labour relief method for labouring woman [17, 22].

The current study reported that obstetric caregivers who had an experience of $6-9$ and $\geq 10$ years were more likely to use labour pain relief methods than those who had $\leq 5$ years' experience $[\mathrm{AOR}=2.56,95 \% \mathrm{CI}=(1.350$ $4.845)$ and $[\mathrm{AOR}=2.50,95 \% \mathrm{CI}=(1.132-5.524)$, respectively. This finding is similar to a study done in the U.S where more experienced nurses provide more labour support [23]. In this study, high patient flow, small number of staff, lack of knowledge, limited skill and unavailability of equipment and drugs for managing labour pain were factors affecting the use of labour pain relief methods. This finding is also consistent with a study done in Tigray region general hospitals, Ethiopia [13], Amhara region referral hospitals, [14], Addis Ababa, Ethiopia [19], Zaria, Nigeria [6] and Saudi Arabia [22].

\section{Limitation of the study}

The results of this study must be interpreted in the light of the following limitations. The study was conducted in public health centers of Amhara Region, Ethiopia. The perspectives of health providers in private health facilities were not explored in the study. The findings of this study are thus mainly applied to obstetric care providers in the study setting. Since the study was cross sectional study, it did not address the cause and effect relationship of the factors and the outcome variables.

\section{Conclusion}

Although labor pain management is accepted and implemented in many countries of the world, pain management during labor is not often practiced. This study is essential as it aims to assess knowledge, and use of labour pain relief methods and associated factors among obstetric caregivers in this study area of Ethiopia.

The current study revealed that the overall use of labour pain by obstetric caregivers was low. Systemic opioid (Pethdine) was reportedly one of the most known pharmacological pain relief methods in this study. Providers' knowledge, attitude and work experience had shown statistical significance with the use of labour pain relief methods. Task-oriented in- service training is thus required to fortify obstetric caregivers' knowledge and attitude towards the use of labour pain relief methods. Regular supervision of obstetric caregivers and logistic supplies and analgesic drugs are also needed for effective labour pain management. Furthermore, researchers in the field are recommended to examine the use of labour pain relief methods from maternal' request point of view.

Overall, this is a fascinating study which has the potential to provide cross cultural education of caregivers from a high income countries who might be caring for immigrant women from low income countries, and may also be a very useful reference for planners of obstetric and midwifery care and education in low income countries.

\section{Abbreviations \\ AOR: Adjusted Odds Ratio; Cl: Confidence Interval; COR: Crude Odd Ratio; HCP: Health Care Providers; OCGs: Obstetric Caregivers; SPSS: Statistical Package for Social Sciences}

\section{Acknowledgements}

We are indebted to Addis Ababa University, College of Health Sciences, School of Nursing and Midwifery for its financial and technical support. We are also very grateful to express our gratitude to East Gojjam Health Bureau and the District health office for their kind assistance during the entire process of the study. The authors are also grateful to the respondents who participated in this study. Special thanks go to the research assistants who participated in data collection.

\section{Authors' contributions}

Bishaw, KA conceptualized the proposal, searched literature, trained field researchers for data collection and wrote the results and discussion sections. He also drafts the first manuscript. Sendo, EG \& Abebe, WS contributed to the design of the study and provided advice as regards methods, data interpretation and analysis. Sendo, EG also critically reviewed and edited the manuscript. All authors read and approved the final manuscript.

\section{Funding}

Funding for this study was made possible through students' grants offered by Addis Ababa University post graduate office. Small grant is given for 
postgraduate students to cover their expenses for data collectors and stationary. No other grants received for the study.

\section{Availability of data and materials}

All the data included in the manuscript can be accessed from the corresponding author with an email address keralemante2010@gmail.com

\section{Ethics approval and consent to participate}

Ethical approval was obtained from Addis-Ababa University and permission letter was secured from East Gojjam zone Health Bureau. Written informed consent was obtained from respondents after giving them information about the study. Finally, the confidentiality, anonymity of all the responses was kept and used only for research purposes.

\section{Consent for publication}

Not applicable

\section{Competing interests}

The authors declare that they have no competing interests.

\section{Author details}

${ }^{1}$ Department of Midwifery, Debre-Markos University, College of Medicine and Health Sciences, Debre-Markos, Ethiopia. ${ }^{2}$ School of Nursing and Midwifery Addis-Ababa University, College of Health Science, Addis Ababa, Ethiopia.

Received: 17 December 2018 Accepted: 26 February 2020

Published online: 23 March 2020

\section{References}

1. Dominick CH, Blyth FM, Nicholas MK. Unpacking the burden: understanding the relationships between chronic pain and co morbidity in the general population. Pain. 2012;153(2):293-304.

2. Dolatian M, Hasanpour A, Heshmat $R$, Alavimajd $H$. The effect of reflexology on labor pain intensity. J Zanjan Univ Med Sci Health Serv. 2010;18:52-61.

3. Lawani LO, Eze JN, Anozie OB, lyoke CA, Ekem NN. Obstetric analgesia for vaginal birth in contemporary obstetrics: A survey of the practice of obstetricians in Nigeria. BMC Pregnancy Childbirth. 2014;14:1.

4. El-Wahab N, Robinson N. Analgesia and anaesthesia in labour. Obstet, Gynaecol Reprod Med. 2011;21(5):137-41.

5. Danziger J. Childbirth myths around the world. Midwives Magazine. 2012;4: 42.

6. Ogboli-Nwasor E, Adaji S, Bature S, Shittu O. Pain relief in labor: a survey of awareness, attitude, and practice of health care providers in Zaria, Nigeria. J Pain Res. 2011;4:227-32.

7. Hodnett ED. Pain and women's satisfaction with the experience of childbirth: A systematic review. Am J Obstet Gynecol. 2002;186:S160-72.

8. Mung'ayi V, Nekyon D, Karuga R. Knowledge, attitude and use of labour pain relief methods among women attending antenatal clinic in Nairobi. East Afr Med J. 2008;85:438-41.

9. Obuna JA, Umeora OUJ. Perception of labor pain and utilization of obstetric analgesia by Igbo women of Southeast Nigeria. J Obstet Anaesth Crit Care. 2014:4(1):18

10. Karuga R, Nekyon D, Mung'ayi V. Knowledge, attitude and use of labour pain relief methods among women attending antenatal clinic in Nairobi. East Afr Med J. 2008;85(9):438-41.

11. Kuti O, Faponle AF. Perception of labor pain among the Yoruba ethnic group in Nigeria. J Obstet Gynaecol. 2006;26:332-3.

12. Waldenstrom U. Experience of labor and birth in 1111 women. J Psychosom Res. 1999;47:471-82.

13. Sahile E, Yemaneh $Y$, Alehegn A, Niguse W, Salahuddin M, et al. Practice of labour pain management methods and associated factors among skilled attendants working at general hospitals in Tigray region, North Ethiopia: hospital-based cross-sectional study design. Health Sci J. 2017:11(4):516.

14. Bitew A, Workie A, Seyum T, Demeke T. Utilization of obstetric analgesia in labor pain management and associated factors among obstetric care givers in Amhara regional state referral hospitals. A Hospital based Cross Sectional Study. Journal of Biomedical Sciences: Northwest Ethiopia; 2016.

15. McCauley M, Stewart C, Kebede B. A survey of healthcare providers' knowledge and attitudes regarding pain relief in labor for women in Ethiopia. BMc pregnancy childbirth. 2017;17(1):56.
16. lliadou M. Labour pain and pharmacological pain relief practice points. Health sci J. 2009:3(Issue 4)

17. EZE Ojerinde O, Onibokun A, Matthew Akpa O. Knowledge and practice of pain management among nurses in labour wards in Ibadan, Nigeria. Afr J Midwifery Womens Health. 2016;10(3):132-7.

18. Lee N, Martensson LB, Kildea S. A cross sectional study of Australian midwives knowledge and use of sterile water injections for pain relief in labour. Women Birth. 2012;25(4):e74-e79.

19. Mulugeta $\mathrm{H}$. The practice of labor analgesia and its perceived barriers among health care providers working in public hospitals of Addis Ababa, Ethiopia; 2016.

20. Aziato L, Kyei AA, Deku G. Experiences of midwives on pharmacological and non-pharmacological labour pain management in Ghana. Reprod Health. 2017;14(1):128.

21. Tasnim S. Perception about pain relief during normal labour among health care providers conducting delivery. Medicine Today. 2010;22(1):20-3.

22. Mona Almushait ${ }^{*}$ RAG. Perception toward Non-Pharmacological Strategies in Relieving Labor Pain: An Analytical Descriptive Study. J Nat Scie Res. 2014 4(2):(ISSN 2225-0921 (Online)).

23. Aschenbrenner AP, Hanson L, Johnson TS, Kelber ST. Nurses' own birth experiences influence labor support attitudes and behaviors. J Obstet Gynecol Neonatal Nurs. 2016:45(4):491-501.

\section{Publisher's Note}

Springer Nature remains neutral with regard to jurisdictional claims in published maps and institutional affiliations.
Ready to submit your research? Choose BMC and benefit from:

- fast, convenient online submission

- thorough peer review by experienced researchers in your field

- rapid publication on acceptance

- support for research data, including large and complex data types

- gold Open Access which fosters wider collaboration and increased citations

- maximum visibility for your research: over $100 \mathrm{M}$ website views per year

At BMC, research is always in progress.

Learn more biomedcentral.com/submissions 